\title{
Ormanların İhmal Edilen Canlıları: Yabani Arılar
}

\author{
Yasemin Güler ${ }^{1, *}$ \\ 'Zirai Mücadele Merkez Araştırma Enstitüsü Müdürlüğ̈̈, 06172, Yenimahalle, Ankara.

\section{Özet}

Bal arısı (Apis mellifera L.) ekosistemlerde polinatör olarak en iyi bilinen ve en yaygın arı türü olmasına rağmen, tüm dünyada bugüne kadar tanımlanmış yaklaşık 16.000 arı türü bulunmaktadır. Çiçekli bitkilerin yaklaşı \% \% 'ninin hayvanlar vasıtasıyla tozlaştığı düşünüldügünde, orman dâhil tüm ekosistemlerde arıların varlığının önemi daha net anlaşılacaktır. Birçok ılıman orman ekosistemi üzerinde antropojenik baskı söz konusudur. Orman alanlarının tarım alanlarına dönüştürülmesi, orman yangınları ve su kaynaklarına yapılan müdahaleler gibi doğrudan veya dolaylı yolla meydana getirilen bu baskl, bitki birliklerinde bozulmalara, dolaylsıyla orman fauna elemanlarında da değișimlere yol açmaktadır. Bitkiler ile arılar arasındaki mutualistik ilişki nedeniyle tahrip olmuş orman alanlarını iyileştirme çalışmalarında yabani arıların habitat ihtiyaçlarının da dikkate alınması, ekosistemin daha çabuk sağlı̆̆na kavuşmasını sağlayacaktır. Çünkü ılıman iklimlerde pek çok orman ağacı rüzgâr yardımı ile tozlaşabilirken, bu alanlardaki bazı yapraklı ă̆aç, çalı ve küçük ă̆aç türleri ile otsu çiçekli bitkilerin pek çoğu arıların yardımına ihtiyaç duyar. Bunlar arasında Castanea sativa Mill. (Anadolu kestanesi), Tilia spp. (Ihlamur), Acer spp. (Akçaağaç türleri), Liquidambar orientalis Mill. (Siğla), Laurus nobilis L. (Defne), Buxus sempervirens L. (Simşir), Arbutus unedo L. (Kocayemiş), Arbutus anrdache L. (Sandal), Cerasus mahalep (L.) Miller (Mahlep), Rhus coriaria L.(Derici sumağı), Cotinus coggygria Scop. (Boyacı sumağı), Tamarix germanica L. (Ilgın), Sorbus aucuparia L. (Kuş üvezi), Erica arborea L. (Ă̆aç funda), Cercis siliquastrum L. (Erguvan), Lavandula spp. (Lavanta), Astragalus spp. (Geven) ve Althaea offinalis L. (Hatmi) sayllabilir. Yaban hayatı için besin ve korunma alanı anlamına gelen bu bitki türlerinin korunması ve varlı̆̆ının sürdürülmesi, erozyonun önlenmesi için de büyük önem taşır. Tahrip olmuş bir ormandaki ağaçların daha iyi yenilenmesi ve ormanın biyolojik çeşitliliğinin korunmasını sağlayacak olan tozlaşmanın gerçekleşmesi, o ormanda yeterli sayı ve çeşitlilikte arı türünün bulunmasina bağlıdır. Bu nedenle, tozlaşma işlevlerinin sürdürülebilirliği için yüksek yoğunluk ve tür çeşitliliğinin koruması gereklidir. Bu da ancak yabani arılar için uygun birbiri ile bağlantıl yarı doğal alanların oluşturulması ve doğal alanların korunması ile mümkün olacaktır.

\section{$\underline{\text { Anahtar Sözcükler }}$}

Polinasyon, Polinatör, Yapraklı Ağaçlar, Otsu Çiçekli Bitkiler

\section{The Neglected Creatures of Forests: Wild Bees}

\begin{abstract}
Although honey bee (Apis mellifera L.) is the best known as pollinator and most common species in ecosystems, there are approximately 16.000 bee species all over the world that have been described so far. The importance of the presence of bees in all ecosystems, including forests, will be more clearly understood when approximately $80 \%$ of flowering plants are thought to be pollinated by animals. There is anthropogenic pressure on many temperate forest ecosystems. This pressure, which is directly or indirectly applied to the forests, such as the conversion of forest areas into agricultural areas, forest fires and interventions to water resources, leads to deterioration of plant associations and therefore to changes in forest fauna elements. Considering the habitat needs of wild bees in their efforts to improve forest areas that are damaged due to the mutualistic relationship between crops and bees, will help the ecosystem to recover more quickly. Because while many forest tree in temperate climates can be pollinated by wind, some of the broad leaved trees, shrubs, small tree species and many herbaceous flowering plants in the same areas need bees for pollination. These include Castanea sativa Mill. (Anatolian chestnut), Tilia spp. (Linden), Acer spp. (Maple species), Liquidambar orientalis Mill. (Sweetgum), Arbutus anrdache L. (Sandalwood), Cerasus mahalep (L.) Miller (Mahalep), Rhus coriaria L. (Sumac), Laurus nobilis L. (Laurel), Buxus sempervirens L. (Boxwood), Arbutus unedo L. (Strawberry tree), Cotinus coggygria Scop. (Smoke tree), Tamarix germanica L. (Tamariks), Sorbus aucuparia L. (Rowan tree), Erica arborea L. (Tree heath), Cercis siliquastrum L. (Redbud), Lavandula spp. (Lavender), Astragalus spp. (Tragacanth) and Althaea offinalis L. (Marshmallow). The protection and preservation of these plant species, which means the area of food and protection for wildlife, is also important for the prevention of erosion. Better refurbishment of the trees in a degraded forest and the maintaining of pollination, which will ensure the preservation of the biological diversity of the forest, depends on the existence of adequate number and variety of bee species in that forest. For this reason, both the protection of high density and species diversity is necessary for the sustainability of pollination services. It is only possible with the establishment of interconnected semi-natural areas suitable for wild bees and the protection of natural areas.
\end{abstract}

\section{$\underline{\text { Keywords }}$}

Pollination, Pollinator, Broad-Leaved Trees, Flowering Plants

\footnotetext{
* Sorumlu Yazar: Tel: +90 (312) 3445994 Faks: +90 (312) 3151531 


\section{Giriş}

Polinatörler, özellikle arılar, karasal ekosistemlerin vazgeçilmez unsurlarıdır. Çünkü çiçekli bitkilerin \%80’i, bugüne kadar tanımlanmış farklı 101.500 polinatör hayvan türü sayesinde tozlaşmaktadır (Michener 2007). Arılar (Hymenoptera: Apoidea), çok sayıda poleni taşımada fonksiyonel rol oynayan çatal şeklindeki kıllarla kaplı bir vücut yapısı, çiçek yapısına özelleşmiş beslenme davranışları ve yavrularını yetiştirmek için çiçeklerin polen ve nektarına bağlı olmaları nedeniyle diğer polinatörlerden daha etkilidirler. Bu polinatör grup, çiçeklerden uçmaları için gerekli enerjiyi veren nektar ve protein kaynağı olarak polen toplayarak iki tip besin elde ederler.

Arılar, bitkisel üretim için esastırlar ve tozlaşma nedeniyle bitki genetik çeşitliliğine katkı sağlarlar. Dünya genelinde insan gıdasının \%90'ı 82 bitki türünden elde edilmektedir ve bunların \%77'si polinatör arıların tozlaştırmasına ihtiyaç duymaktadır. Yem bitkilerinin tozlaşmasındaki ekolojik nişi nedeniyle, hayvansal üretimde de dolaylı olarak etkileri vardır. Bu canlılar sadece tarımsal ekosistemlerin değil, tropikal ormanlardan çöllere kadar pek çok farklı ekosistemin de önemli elemanlarıdır ve onların sağladığı katkıya değer biçilemez. Çöllerde veya kurak alanlardaki çalılıklar ve çiçekli otsu bitkiler, erozyonun önlenmesindeki fonksiyonlarının yanı sıra yuvalanma ve beslenme alanı oluşturmaları nedeniyle yaban hayatının da devamlılığı için önem arz ederler. Bu bitkiler, arı tozlaşmasına ihtiyaç duyan türlerden oluşur. Ayrıca arılar, ekosistemlerin en önemli sağlık göstergeleridir. Karmaşık yaşam döngüleri, besin ve yuvalanma için özel koşullara gereksinim duymaları nedeniyle ekosistem sağlığının izlenmesinde biyolojik indikatör olarak kullanılırlar (Oertli vd. 2005).

\section{Orman Ekosisteminde Arılar}

Ilıman iklimlerde pek çok orman ağacı rüzgâr ile tozlaşabilirken, bu alanlardaki geniş yapraklı ağaçlar, çalı ve çiçekli otsu bitkilerin pek çoğu arıların işbirliğine ihtiyaç duyarlar. Bu bitki türlerinden bazılarına Tablo 1, 2 ve 3'de yer verilmiştir. Tozlaşmada arılarla işbirliğine ihtiyaç duyan bu tür listesinin oluşturulmasında Fern (2002) ve Sorkun (2008)'dan yararlanılmıştır. Orman ekosisteminde doğal formları ile sıklıkla karşılaşılan bu türlerin pek çoğu, günümüzde süs bitkisi olarak da kullanılmaktadır.

Tablo 1: Tozlaşmaları için arıların yardımına ihtiyaç duyan bazı geniş yapraklı ağaç türleri

\begin{tabular}{|l|l|l|l|}
\hline No & Bitki & Bitki Adı & Türkçe Adı \\
\hline $\mathbf{1}$ & Ağaç & Acer negundo & Akçaağaç \\
\hline $\mathbf{2}$ & Ağaç & Acer platanoides & Çınar Yapraklı Akçaağaç \\
\hline $\mathbf{3}$ & Ağaç & Aesculus hippocastanum & Beyaz Çiçekli Atkestanesi \\
\hline $\mathbf{4}$ & Ağaç & Aesculus x carnea & Kırmızı Çiçekli Atkestanesi \\
\hline $\mathbf{5}$ & Ağaç & Ailanthus altissima & Kokarağaç \\
\hline $\mathbf{6}$ & Ağaç & Albizia julibrissin & Mimoza \\
\hline $\mathbf{7}$ & Ağaç & Castanea sativa & Kestane \\
\hline $\mathbf{8}$ & Ağaç & Catalpha bignonoides & Katalpa \\
\hline $\mathbf{9}$ & Ağaç & Celtis australis & Çitlembik \\
\hline $\mathbf{1 0}$ & Ağaç & Cercis siliquastrum & Erguvan \\
\hline $\mathbf{1 1}$ & Ağaç & Elaeagnus angustifolia & Ĭğde \\
\hline $\mathbf{1 2}$ & Ağaç & Eucalyptus gunnii & Okaliptus \\
\hline $\mathbf{1 3}$ & Ağaç & Koelreuteria paniculata & Güveyi Kandili \\
\hline $\mathbf{1 4}$ & Ağaç & Laburnum alpinum & Sarı Salkım \\
\hline $\mathbf{1 5}$ & Ağaç & Magnolia Grandiflora & Manolya \\
\hline $\mathbf{1 6}$ & Ağaç & Malus floribunda & Süs Elması \\
\hline $\mathbf{1 7}$ & Ağaç & Prunus amygdalus & Badem \\
\hline $\mathbf{1 8}$ & Ağaç & Prunus cerasifera & Süs Eriği \\
\hline $\mathbf{1 9}$ & Ağaç & Prunus serrulata & Süs Kirazı \\
\hline $\mathbf{2 0}$ & Ağaç & Robinia pseudoacacia & Yalancı Akasya \\
\hline $\mathbf{2 1}$ & Ağaç & Salix alba & Ak Söğüt \\
\hline $\mathbf{2 2}$ & Ağaç & Sophora japonica & Sofora \\
\hline $\mathbf{2 3}$ & Ağaç & Sorbus domestica & Üvez \\
\hline $\mathbf{2 4}$ & Ağaç & Tilia platyphyllos & Ihlamur \\
\hline
\end{tabular}


Tablo 2: Tozlaşmaları için arıların yardımına ihtiyaç duyan bazı çalı türleri

\begin{tabular}{|c|c|c|c|}
\hline No & Bitki & Bitki Adı & Türkçe Adı \\
\hline $\mathbf{1}$ & Çalı & Aucuba japonica & Japon Akübası \\
\hline 2 & Çalı & Berberis thunbergi & Kırmızı Berberis \\
\hline 3 & Çalı & Buddleia davidii & Kelebek Çalısı \\
\hline 4 & Çalı & Buxus sempervirens & Şimşir \\
\hline 5 & Ağaç/Çalı & Caesalpinia gilliesii & Cennetkuşu \\
\hline 6 & Çalı & Camellia japonica & Kamelya \\
\hline 7 & Çalı & Campsis radicans & Acem Borusu \\
\hline 8 & Çalı & Chaenomeles japonica & Bahar Dalı \\
\hline 9 & Çalı & Cornus alba & K1z1lc1k \\
\hline 10 & Çalı & Cotoneaster dammeri & Dağ Muşmulası \\
\hline 11 & Çalı & Cotoneaster horizantalis & Yayılıcı Dağ Muşmulası \\
\hline 12 & Çalı & Erica arborea & Funda \\
\hline 13 & Çalı & Euonymus fortunei & Yayılıcı Taflan \\
\hline 14 & Çalı & Euonymus japonica aurea & Sarı Alacalı Taflan \\
\hline 15 & Çalı & Forsythia viridissima & Altınçanı \\
\hline 16 & Çalı & Hedera helix & Kaya Sarmaşı̆̆ı \\
\hline 17 & Çalı & Hypericum calycinum & Koyun Kıran Çalısı \\
\hline 18 & Çalı & Ilex aquifolium & Çoban Püskülü \\
\hline 18 & Çalı & Jasminum officinale & Yasemin \\
\hline 19 & Çalı & Keria japonica & Kanarya Gülü \\
\hline 20 & Çalı & Ligustrum vulgare & Kurtbağrı \\
\hline 21 & Çalı & Lonicera caprifolium & Hanımeli \\
\hline 22 & Çalı & Lonicera caucasica & Kafkas Hanımelisi \\
\hline 23 & Çalı & Mahonia aquifolium & Mahonya \\
\hline 24 & Çalı & Nandina domestica & Cennet Bambusu \\
\hline 25 & Çalı & Parthenocissus quinquefolia & Amerikan Sarmaşığ1 \\
\hline 26 & Çalı & Pyracantha coccinea & Ateş Dikeni \\
\hline 27 & Çalı & Rosa meiland & Peyzaj Gülü \\
\hline 28 & Çalı & Rosmarinus officinalis & Yeşilpüren \\
\hline 29 & Çalı & Symphoricarpus albus & İnci Çalısı \\
\hline 30 & Çalı & Syringa vulgaris & Leylak \\
\hline 31 & Çalı & Tamarix tetrandra & Ilgin \\
\hline 32 & Çalı & Vibirnum opulus & Kartopu \\
\hline 33 & Çalı & Vibirnum tinus & Kartopu \\
\hline
\end{tabular}

Bir habitattaki arı çeşitliliğini etkileyen en önemli biyotik faktör bitki çeşitliliği iken, sıcaklık ve 1şık miktarı ise en önemli abiyotik faktörlerdir. Bu nedenle, diğer polinatörler gibi arılar da, orman türü veya coğrafi bölgeye bakılmaksızın açık orman alanlarında hem yoğunluk hem de tür sayısı bakımından daha zengin bulunmaktadır (Roberts vd. 2017). Orman kanopilerinin altında bulunan yoğun çalı tabakaları ve otsu bitki örtüsü, polinatör çeşitliliğini olumsuz yönde etkilemektedir. Hanula vd. (2016), Amerika Birleşik Devletleri'nin Piedmont bölgesine özgü yedi orman alanını ele aldığı çalışmalarında, daha düşük yaprak yoğunluğu olan alanlarda arıların daha fazla sayı ve tür zenginliğine sahip olduğunu belirlemişlerdir. En yüksek tür zenginliği ve arı bolluğu, açık kanopili ve kısmi çalı örtüsü olan olgun çam ormanlarında meydana gelmiştir. 
Tablo 3: Tozlaşmaları için arıların yardımına ihtiyaç duyan bazı tek ve çok yıllık çiçekli bitki türleri

\begin{tabular}{|c|c|c|c|}
\hline No & Bitki & Bitki Adı & Türkçe Adı \\
\hline 1 & Tek yıllık & Ageratum houstonianum & Vapur Dumanı \\
\hline 2 & Çok yıllık & Althaea rosea & Gül Hatmi \\
\hline 3 & Çok yıllık & Alyssum saxatile & Kuduz Otu \\
\hline 4 & Çok yıllık & Antirrhinum majus & Aslanağzı \\
\hline 5 & Çok yıllık & Aptenia cordifolia & Katırtırnağ 1 \\
\hline 6 & Çok yıllık & Aster amellus & Ayıkulağ 1 \\
\hline 7 & Çok yıllık & Aster laevis & Aster \\
\hline 8 & İki yıllık & Aster trifolium & Sahilasteri \\
\hline 9 & Çok yıllık & Bellis perennis & Koyungözü \\
\hline 10 & Çok yıllık & Brassica oleracea & Süs Lahanası \\
\hline 11 & Tek yıllık & Calendula officinalis & Portakal Nergisi \\
\hline 12 & Tek yıllık & Callistephus sinensis & Saraypatı \\
\hline 13 & Tek yillık & Celosia crisata & Horoz İbiği \\
\hline 14 & Çok yıllık & Cerastium tomentosum & Farekulağ \\
\hline 15 & Çok yıllık & Chrysanthemum indicum & Kasımpatı \\
\hline 16 & Tek yıllık & Cineraria maritima & Kül Çalısı \\
\hline 17 & Çok yıllık & Dahlia sp. & Yildız Çiçeği \\
\hline 18 & Tek yıllık & Datura metel & Boruçiçeği \\
\hline 19 & Çok yıllık & Dianthus barbatus & Hüsnü Yusuf \\
\hline 20 & Çok yıllık & Dianthus caryophillus & Karanfil \\
\hline 21 & Çok yıllık & Echinacea purpurea & Ekinezya \\
\hline 22 & Tek/Çok Yillık & Fuchsia sp. & Küpe \\
\hline 23 & Çok yıllık & Gaillardia grandiflora & Gayretçiçeği \\
\hline 24 & Tek/Çok Yillık & Gazania nivea & Koyungözü \\
\hline 25 & Çok yıllık & Gerbera jamesonii & Gerbera \\
\hline 26 & Çok yıllık & Hebe veronica & Hebe \\
\hline 27 & Tek yıllık & Impatiens balsamina & Kınaçiçeği \\
\hline 28 & Çok yıllık & Iris germanica & Süsen \\
\hline 29 & Çok yıllık & Lavandula angustifolia & Lavanta \\
\hline 30 & Çok yıllık & Petunia hybrida & Petunya \\
\hline 31 & Tek/Çok Y1llık & Primula hortensis & Çuha Çiçeği \\
\hline 32 & Tek/Çok Yillık & Salvia splendens & Ateş Çiçeği \\
\hline 33 & Çok yıllık & Santolina chamaecyparissus & Lavantin \\
\hline 34 & Çok yıllık & Sedum reflexum & Damkoruğu \\
\hline 35 & Çok yıllık & Senecio bicolor & Bahçe Kül Çiçeği \\
\hline 36 & Tek yıllık & Tagetes erecta & Kadife Çiçeği \\
\hline 37 & Çok yıllık & Thymus vulgare & Kekik \\
\hline 38 & Çok yıllık & Verbena $x$ hybrida & Mine \\
\hline 39 & Çok yıllık & Vinca major & Cezayir Menekşesi \\
\hline 40 & Çok yıllık & Vinca rosea & Pervane \\
\hline 41 & Tek yıllık & Viola tricolor & Hercai Menekşe \\
\hline 42 & Tek yıllık & Zinnia elegans & Zinya \\
\hline
\end{tabular}

Açık orman alanlarında arı çeşitliliğinin daha yüksek olmasının en önemli nedeni, atasal bir karakter olarak arı türlerinin pek çoğunun toprak zeminde yuvalanıyor olmasıdır (Michener 2007). Bir habitat içerisindeki sıcaklık ve 1şık miktarı, arıların toprağa bağlanmasını etkileyen en önemli faktörlerdir. Hatta toprağa yuvalanan arıların bol güneşe maruz kalan yamaçlarda daha fazla yuvalandıkları da bilinmektedir. Arıların \%30’u ise, içi boş bitki sapları, ağaç gövdelerinde daha önce Kınkanatlıların (Coleoptera), kuşların veya insanların açmış oldukları oyuklara yuvalanırlar. Ağaç gövdelerine yuvalanan arılar genellikle toprağa yakın alanlara yuva inşa etmeyi tercih ederler, ancak gövdenin üst bölümlerinde de ar1 yuvalarına rastlanır (Bradbear 2009). 
Yoğun bitki örtüsü yerine güneş ışığının doğrudan ulaştığı, çiçekli bitki çeşidinin yüksek olduğu alanlar arıların tercih ettiği habitatları oluşturur. Bu koridor alanlar, arılar için uygun bir mikroklima oluşturmanın yanı sıra eş bulmayı ve ziyaret edilen bitki ile yuva arasında gezinmeyi de kolaylaştırır (Hanula vd. 2016). Bir ormanda yeterli miktarda arı çeşidi bulunması, ağaçların daha iyi yenilenmesi ve ormanın biyoçeşitliliğinin korunmasını sağlayan daha iyi bir tozlaşma servisinin kurulmasına olanak sağlar. Bitkilerin genlerini sürekli olarak karıştırmanın tek yolu, bir bitkinin poleninin diğerine arılar tarafından taşındığı ve böylece genetik olarak farklı hale geldiği yabancı tozlaşmadır. Bu şekilde, en azından bazı bitkiler yaşam rekabeti içinde hayatta kalmaları için daha büyük bir şansa sahip olurlar (Bradbear 2009).

\subsection{Açık orman habitatları}

Açık orman habitatları, düzenli olarak yapılan seyreltmeler, orman yol kenarları, enerji nakil hatlarının oluşturduğu koridorlar ile kontrollü/kontrolsüz orman yangınları ile oluşabilir. Bu alanlar hem mikroklimatik hem de daha geniş floral kaynak barındıran alanlar yaratır. Bu da daha fazla sayı ve çeşitlilikte polinatör tür demektir. Kısaca açık koridor alanları, yoğun ormanlık alanlarda da polinasyon işlevini sürdüren habitatlar oluşturur. Ülkemizde son yıllarda bozuk vasıflı ormanların rehabilitasyonu için bal ormanları oluşturma görüşü ön plana çıkmıştır. Bal ormanları, bozuk alanlara bal arılarının nektar ve polen kaynağı olan ağaç, otsu ve çalı formundaki bitkilerin dikilmesi ile oluşturulur. Bu alanlar, yabani arılar için de önemli besin kaynağı ve yuvalanma alanları oluşturur. Bal ormanlarının kurulmasında, öncelikli amaç bal üretimi ve bu sayede bölge halkının gelir seviyesinin yükseltilerek ormanlar üzerindeki baskının azaltılmasıdır (OGM 2013). Belki de bu alanların en önemli fonksiyonu, yaban hayatın korunması ve toprak koruma ile erozyon kontrolünde sağladığı faydadır.

Ormanlarda düzenli olarak yapılan seyreltme işlemleri, bitki sağlığını geliştirmek, büyüme oranlarını artırmak ve zararlı böcek salgınlarını azaltmak için uygulanır. Fettig vd. (2007) ile Nowak vd. (2015) çalışmalarında açık orman alanlarının zararlı ve patojen türlerin yayılışında sınırlayıcı faktör olduğunu bildirmektedirler. Fettig vd. (2007), ibreli ağaçlardan oluşan yoğun orman alanlarındaki çalı tabakalarının Kabuk böceklerine (Coleoptera: Curculionidae: Scolytinae) karşı daha hassas olduğunu ve Kabuk böcek hasar riskini azaltmak için seyreltmenin, en yaygın olarak kullanılan ve etkili bir orman yönetim araçlarından biri olduğunu ifade etmektedirler. Nowak vd. (2015), seyreltmenin yanı sıra denetimli yangınlarında, Güney çam böceği (Dendroctonus frontalis Zimmermann) istilasının olasılığını azaltabileceğini bildirmektedir. Orman yangınları ekosistem üzerinde genellikle pozitif etki oluşturmasına rağmen yangınının büyüklüğü ve sıklığı önemli bir sınırlayıcı faktördür. Özellikle sadece birkaç bitki türüne özelleşmiş oligolektik arı türleri için büyük yangınlar, özelleştiği bitki türlerinin yok olmasına dolayısıyla kendi popülasyonun devamlılı̆̆ını da riske atmaktadır.

Ormanlarda polinatörlerin korunması ve sürdürülebilirliğinin sağlanması, bu alanlara komşu tarımsal ekosistemlerde de olumlu etki yarattığı çeşitli çalışmalarla ortaya konulmuştur. Ricketts (2004) tarafindan yürütülen bir çalışmada, yoğun tarımsal faaliyetlerin yürütüldüğü kahve bahçelerinde arı çeşitliliğinin ormanlık alanlara yaklaştıkça arttığı, bunun da kahve veriminde yaklaşık \%20'lik bir artışa karşılık geldiği belirlenmiştir. Benzer bir çalışma kolza tohumu yetiştirilen tarlalarda yürütülmüş ve yine arılarda gerek yoğunluk gerekse çeşitlilik bakımından ormanlık alanlara yaklaşmanın pozitif etki yarattı̆̆ı saptanmıştır (Bailey vd. 2014).

\section{Sonuç}

Polinatör habitatını koruma ve geliştirme çabaları, aslında orman sağlığını korumaya yönelik faaliyettir. Tozlaşma hizmetlerinin korunması ve devamlılığının sağlanması için, yabani arıların yüksek tür ve gen zenginliğini koruması şarttır. $\mathrm{Bu}$ özellikle genç veya tahrip olmuş ormanlık alanların iyileşme sürecini hızlandıracak bir adımdır. Tahrip olmuş bir ormandaki ağaçların daha iyi yenilenmesi ve ormanın biyolojik çeşitliliğinin korunmasını sağlayacak olan tozlaşmanın gerçekleşmesi pek çoğunu arıların oluşturduğu polinatörlerin varlığına bağlıdır. Bu da ancak yabani arılar için uygun birbiri ile bağlantılı yarı doğal alanların oluşturulması ve doğal alanların korunması ile mümkün olacaktır (Taki vd. 2013).

Ormanlarda gençleştirme çalışmaları sırasında, odun dokuya yuvalanan arı türlerini ortama çekmek için uygun yuvalanma ortamları geliştirilebilir. Bunu ölü ağaçların bir kısmının ortamda tutulması ve güneşe maruz kalan yerlerde yüksek kütüklerin kesilmesiyle sağlamak mümkündür (Hanula vd. 2016).

Kurak mevsimlerde orman yangınlarının sık yaşandığı savanlarda, yüksek ağaç gövde ve dallarına yuvalanmak bazı arı türleri için bir avantaj sağlamaktadır (Bradbear 2009). Bu bölgelerde arı çeşitliliğinin devamlılığı için uzun ağaçların korunması faydalı olacaktır.

Ayrıca orman yol kenarındaki koridorlar, bitişik ormanların bitki örtüsü incelenerek, bölgeye uygun çiçekli otsu bitkilerle zenginleştirilerek kenar etkisi artırılabilir. Böylece polinatör dostu yaşam alanları oluşturulabilir. Bu özellikle şehir ormanları ile şehir park ve bahçelerinde de uygulanması mümkün olan bir seçenektir. Çünkü bu habitatlar, şehirli arı türlerinin sürdürülebilirliğini sağlayan sığınak alanlarıdır. 


\section{Kaynaklar}

Bailey S., Requier F., Nusillard B., Roberts S.P.M., Potts S.G., Bouget C., (2014), Distance from forest edge affects bee pollinators in oilseed rape fields, Ecology and Evolution, 4(4), 370-380.

Bradbear N., (2009), Bees and their role in forest livelihoods: a guide to the services provided by bees and the sustainable harvesting, processing and marketing of their products, FAO, Rome, 194ss.

Fern K., (2002), Plants For A Future: Edible, Medicinal and Useful Plants for a Healthier World, https://pfaf.org/USER/ cmspage.aspx?pageid=32, [Erişim 21 Ocak 2018].

Fettig C.J., Klepzig K.D., Billings R.F., Munson A.S., Nebeker T.E., Negrón J.F., Nowak J.T., (2007), The effectiveness of vegetation management practices for prevention and control of bark beetle infestations in coniferous forests of the western and southern United States, Forest Ecology and Management, 238(1-3): 24-53.

Hanula J.L., Ulyshen M.D., Horn S., (2016), Conserving pollinators in North American forests: a review, Natural Areas Journal, 36(4), 427-439.

Michener C.D., (2007), The bees of the World, John Hopkins Univ. Press, Balitimor, USA, 953ss.

Nowak J., Meeker J.R., Coyle D.R., Steiner C.A., Brownie C., (2015), Southern pine beetle infestations in relation to forest stand conditions, previous thinning, and prescribed burning: Evaluation of the southern pine beetle prevention program, Journal of Forestry, 113: 454-462.

OGM, (2013), Bal ormanı eylem planı (2013-2017), Orman Genel Müdürlüğü, Ankara, 136ss.

Oertli S., Müller A., Dorn S., (2005), Ecological and seasonal pattern in the diversity of a species-rich bee assemblage (Hymenoptera: Apoidea: Apiformes), Eur. J. Entomol., 102: 53- 63.

Ricketts T.H., (2004), Tropical Forest Fragments Enhance Pollinator Activity in Nearby Coffee Crops, Conservation Biology, 18(5), $1262-1271$.

Roberts H.P., King D.I., Milam J., (2017), Factors affecting bee communities in forest openings and adjacent mature forest, Forest Ecology and Management, 394, 111-122.

Sorkun K., (2008), Türkiye'nin Nektarlı Bitkileri Polenleri ve Balları, Palme Yayınları, Ankara, 352ss.

Taki H., Okochi I., Okabe K., Inoue T., Goto H., (2013), Succession influences wild bees in a temperate forest landscape: the value of early successional stages in naturally regenerated and planted forests, PLoS ONE, 8(2): e56678. 